\title{
Processing and Validation of Whey-Protein-Coated Films and Laminates at Semi-Industrial Scale as Novel Recyclable Food Packaging Materials with Excellent Barrier Properties
}

\author{
E. Bugnicourt, ${ }^{1}$ M. Schmid, ${ }^{2,3}$ O. Mc. Nerney, ${ }^{1}$ J. Wildner, ${ }^{4}$ L. Smykala, ${ }^{4}$ \\ A. Lazzeri, ${ }^{5}$ and P. Cinelli ${ }^{5}$ \\ ${ }^{1}$ Innovació i Recerca Industrial i Sostenible (IRIS), Parc Mediterrani de la Tecnologia, Avenida Carl Friedrich Gauss No. 11, \\ 08860 Castelldefels, Spain \\ ${ }^{2}$ Material Development Department, Fraunhofer Institute for Process Engineering and Packaging IVV, Giggenhauser Straße 35, \\ 85354 Freising, Germany \\ ${ }^{3}$ Chair of food packaging technology, Technische Universität München, Weihenstephaner Steig 22, 85354 Freising, Germany \\ ${ }^{4}$ Food Technology and Bioprocess Engineering, ttz Bremerhaven, Fischkai 1, 27572 Bremerhaven, Germany \\ ${ }^{5}$ Department of Chemical Engineering, Industrial Chemistry and Materials Science, University of Pisa, Via Diotisalvi No. 2, \\ 56126 Pisa, Italy
}

Correspondence should be addressed to E. Bugnicourt; ebugnicourt@iris.cat and M. Schmid; markus.schmid@ivv.fraunhofer.de

Received 25 August 2012; Accepted 5 January 2013

Academic Editor: Wen-Hua Sun

Copyright (C) 2013 E. Bugnicourt et al. This is an open access article distributed under the Creative Commons Attribution License, which permits unrestricted use, distribution, and reproduction in any medium, provided the original work is properly cited.

\begin{abstract}
A biopolymer coating for plastic films was formulated based on whey protein, and its potential to replace current synthetic oxygen barrier layers used in food packaging such as ethylene vinyl alcohol copolymers (EVOH) was tested. The whey-coating application was performed at semi-industrial scale. High barrier to oxygen with transmission rate down to ranges of $1 \mathrm{~cm}^{3}$ (STP) $\mathrm{m}^{-2} \mathrm{~d}^{-1}$ bar ${ }^{-1}$ at $23^{\circ} \mathrm{C}$ and $50 \%$ relative humidity (r.h.) but interesting humidity barrier down to ranges of $3 \mathrm{~g} \mathrm{~m}^{-2} \mathrm{~d}^{-1}$ (both normalized to $100 \mu \mathrm{m}$ thickness) were reached, outperforming most existing biopolymers. Coated films were validated for storing various food products showing that the shelf life and sensory attributes were maintained similar to reference packaging films while complying with food safety regulations. The developed whey coating could be enzymatically removed within 2 hours and is therefore compatible with plastic recycling operations to allow multilayer films to become recyclable by separating the other combined layers. A life cycle assessment was performed showing a significant reduction in the environmental impact of the packaging thanks in particular to the possibility of recycling materials as opposed to incinerating those containing EVOH or polyamide (PA), but due to the use of biosourced raw materials.
\end{abstract}

\section{Introduction}

The high requirements on food packaging material in terms of barriers against light, moisture, water vapour, and gases are specific to the type of food to be packed in order to guarantee a quality product throughout its shelf life. Protection against oxygen is a key factor. The appropriate packing atmosphere is needed to avoid colour or taste deviation, oxidation of grease, formation of microorganisms, or degrading nutrients.
On the one hand, to achieve these requirements coextruded or laminated multilayer plastic films are widely used in the packaging industry whereby ethylene vinyl alcohol copolymers (EVOH) are often used to obtain a sufficient oxygen barrier.

On the other hand, the plastic recycling process generally consists of the preliminary separation of the different types of polymers, the shredding of the plastic items, the washing of the resulting flakes, and their recompounding and processing into new, lower demanding applications. In such a context, 
while the combination of various layers is required for good food preservation, the recyclability of multilayer packaging is compromised, as monomaterials of high purity are needed for reprocessing.

Furthermore, as opposed to most synthetic plastics used as packaging materials, most of the currently available bioplastics do not meet the key requirements of food packaging especially in terms of barrier properties. Therefore, research into sustainable packaging materials that maintain the performance of their composite structures has been recently intensified. An example is the present study, which aimed at developing a whey protein coating for plastic films capable of replacing synthetic oxygen-barrier layers such as EVOH used in multilayer packaging. This whey protein coating would represent a new application for this agrofood industry waste while safeguarding the performance and enhancing the recyclability of multilayer films.

Indeed, whey is a by-product of cheese manufacturing that contains approximately $7 \%$ dry matter. In general the dry matter includes $13 \%$ proteins, $75 \%$ lactose, $8 \%$ minerals, approximately $3 \%$ organic acids, and less than $1 \%$ fat. Whey protein can be separated and purified from the liquid whey using a membrane filtration process followed by spray drying to obtain either Whey Protein Concentrate (WPC, protein concentration $65-80 \%$ in dry matter d.m.) or Whey Protein Isolate (WPI, protein concentrations over $90 \%$ in d.m.). In general, whey proteins are used as additives in the agrofood industry; however, $40-50 \%$ of the 50 million tons of whey produced annually in Europe are still unprocessed [1-3]. In addition, the generated waste can be highly polluting if not properly handled due to the high organic content of whey.

This study builds on past literature showing that edible coatings made of whey proteins offered good aroma, fat, humidity, and oxygen barriers on, among others, peanuts, salmon, fruits, or cereals. Such coatings helped to improve the shelf life of, for example, peanuts, by retarding the lipid oxidation causing rancidity [4]. In addition, these edible films were reported not to modify the sensory attributes of the coated good or its aspect, while providing some health benefits for the consumer [5]. A number of authors have also reported the good barrier properties of whey protein-based coating on paper [6,7], but also on plastic substrates [8-12]. As yet, none of these academic studies has been routed to the industry and the present study demonstrates the scale-up ability.

\section{Materials and Methods}

2.1. Coating Formulation. The main raw material used to make the coating solution was WPI BiPro from Davisco Foods International (Le Sueur) (d.m. 93.52\%; protein 98.74\% of d.m.; fat $=0.21 \%$ of d.m.; minerals $=1.94 \%$ of d.m.; Lactose $=0.02 \%$ of d.m. with $22.8 \%$ of $\alpha$-lactalbumin and $67.7 \%$ of $\beta$-lactoglobulin). As previously reported at the lab and pilot levels [13], besides using BiPro, different types of sweet and sour whey proteins were isolated by membrane filtration in order to obtain pure whey protein. Various modification techniques, like chemical modification, enzymatic hydrolysis, and high pressure treatments, were evaluated to improve film-forming behaviour.

Plasticizers were added to prevent brittleness of the protein coatings: sorbitol and glycerol (food grades) were both supplied by Panreac Quimica. Additional additives were tested. The effect of the nature and modification of the proteins, $\mathrm{pH}$ value, and minerals/salts addition were screened [13].

The thermomechanical and optical measurements results showed an excellent gloss and high transparency of coated poly(ethylene terephthalate) (PET) films. A very good adhesion between the coating and the PET substrate was also reported [13].

The most promising formulations among those evaluated at pilot scale were selected for scaling up, which is the objective of the present paper. The different whey-additives compositions previously described were weighted at different ratios with dry matters of 10 to $50 \%$, mixed into distilled water, and agitated at $4500 \mathrm{rpm}$ using an agitator RZR 1 from Heidolph Instruments, until full dissolution. The solution was outgassed ultrasonically and left at rest.

The viscosity of whey-protein-based coating solutions was measured with a Brookfield viscosimeter at $23^{\circ} \mathrm{C}$ temperature at various rotational speeds $(0-100 \mathrm{rpm})$ using different spindles (numbers 1 and 2) to assess their applicability.

Details on the exact composition and preparation conditions can be found in the patent application [14] but general trends and ranges as well as the properties of the resulting coated films are described here.

2.2. Coating Application. The substrate used for applying the whey coating in the trials reported here was PET of $20 \mathrm{~cm}$ width and $12 \mu \mathrm{m}$ thickness (reference PXE from Nuroll $M \& G)$.

The coating solutions were applied at semi-industrial rates of 10-30 meters per minute using a tailor-made application and drying prototype (Innovació i Recerca Industrial i Sostenible, Castelldefels, Spain). The drier combines various drying methods (hot air and infra red) to optimize drying speed and energy consumption. Eco-efficiency of the drying process is important in order to minimise the environmental impact of this manufacturing stage on the material life cycle analysis. Controlled drying and concomitant curing/partial crosslinking of the coating are required to obtain the correct structure of the protein-based coating on the film (following patent pending process [14]), maintaining the excellent properties found at lab and pilot scale and consequently determining the suitability of the material for packaging application [15].

As shown in Figure 1, the process prototype for wheycoating application allowed the following successive operations to be performed: film unwinding, corona pretreatment of the film, coating application, drying, stabilization, and winding of the coated film.

A ceramic-coated steel roller coater with various engraved patterns was tested and allowed to coat 20-40 gram per square meter $\left(\mathrm{g} \mathrm{m}^{-2}\right)$ of wet solution on the substrate. 

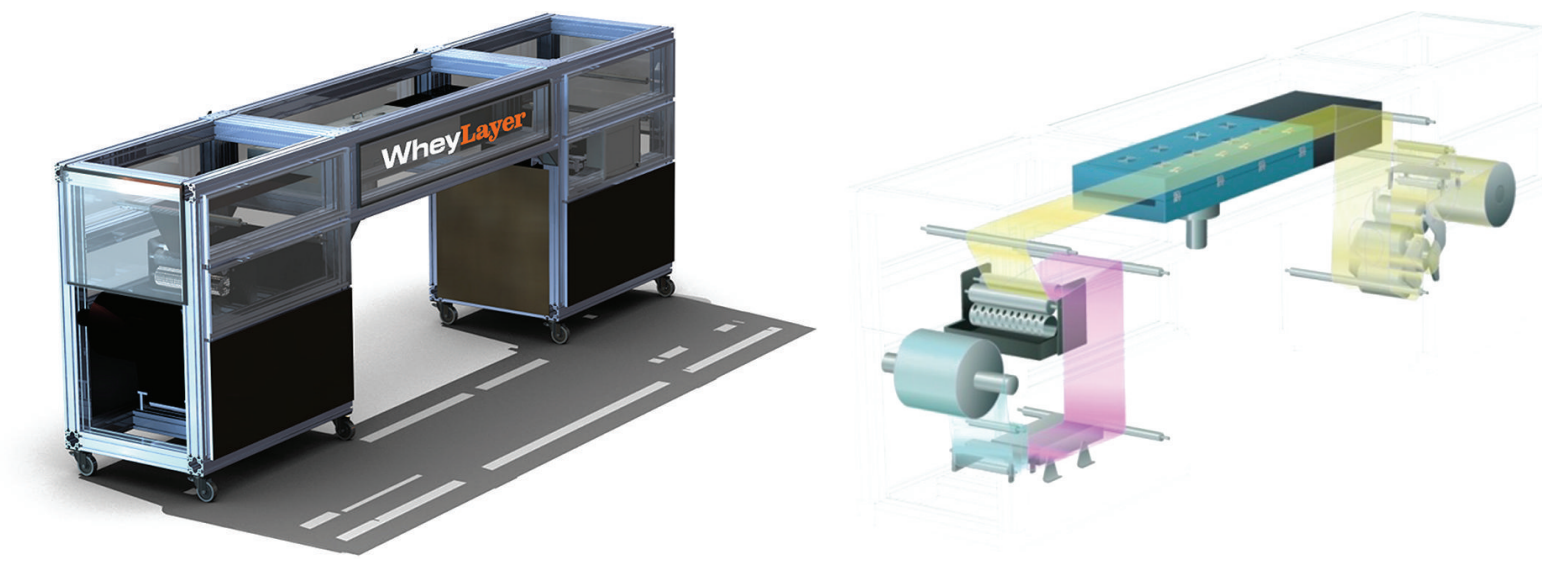

FIGURE 1: Whey-coating application and drying process prototype (external and internal views).

The drying tunnel was composed of several infra red lamps (power up to $1 \mathrm{~kW}$ each and variable emission peak wavelength). The heat exchanged by radiation in this segment allowed a fast warming up of the coating solution. Then several heated fans allowed the drying to be finalised by forced convection (air flow of $1600 \mathrm{~m}^{3} \mathrm{~h}^{-1}$ ). The drying profile was optimized in terms of temperature to result in suitable coating properties while avoiding damage to the substrate by excessive heat independently of its thickness, glass transition temperature, and surface properties.

A corona pretreatment was performed in order to obtain sufficient wettability and adhesion of the coating layer on the substrate. Wettability properties of PET and coated PET were studied by measuring the contact angle of water droplets onto the films using a SEE System (Surface Energy Evaluation System from Advex Instruments s.r.o., Czech Republic). For every sample, 6 parallel measurements were performed and average values were reported.

Resulting coated films were either directly characterised or assessed after lamination with polyethene (PE, $20 \mu \mathrm{m}$ ) as a sealing layer using Liofol UK 3640/UK 6800 by Henkel KGaA (Düsseldorf) as an adhesive.

2.3. Evaluation of Coated Films. The coating amount applied on the coated films was evaluated taking into account the weight difference between the uncoated substrate and the coated one. A few samples of 10 per $10 \mathrm{~cm}$ of coated and virgin PET were cut and weighted using a scale with a precision of tenth of mg (Mettler Toledo XA105DU). The result of the difference in weight was expressed in $\mathrm{g} \cdot \mathrm{m}^{-2}$ to assess the deposition efficiency of the coating head.

The residual moisture of the coated film was measured by DSC (Differential Scanning Calorimetry, DSC1 from Mettler Toledo) by measuring the enthalpy of water evaporation to assess the drying efficiency of the whey-coating application and drying process prototype in comparison with a virgin substrate film used as a reference.

2.4. Barrier Properties. Oxygen permeability was measured according to 2 complementary methods.
First, an internal optical cell oxygen transmission rate (OTR) measurement was performed at $23^{\circ} \mathrm{C}$ and $0 \%$ r.h. The coated samples were measured in custom-made measuring stainless steel cells. A defined measurement volume is very important for this measurement. Therefore, the film samples were fixed between the upper and lower chambers. Furthermore, the cells have two gas connections for each chamber for flushing both cells first with nitrogen (zero value) and afterwards for flushing the lower cell with oxygen. The principle of measurement is based on the effect of dynamic luminescence quenching by molecular oxygen. Therefore, a relation exists between oxygen concentration in the sample and luminescence intensity as well as luminescence lifetime and the OTR can be calculated [16].

Second, OTR was evaluated according to standard method DIN 53380-3 (DIN, 1998) at $23^{\circ} \mathrm{C}$ and $50 \%$ r.h. using an Ox-Tran 2/20 equipment from Mocon. The coated side of the films was exposed to flowing oxygen gas and the other side to flowing nitrogen gas. Resulting oxygen permeability of multilayer films was deduced in terms of $\mathrm{cm}^{3} / \mathrm{m}^{2} \cdot d \cdot b a r$ and used for further calculations regarding permeability of the single whey protein layer.

Indeed, a coated film can be considered as a 2-layer structure, comparable to a laminated material $[7,17]$ and the following equations can be used:

$$
\begin{gathered}
\frac{d}{P}=\frac{d_{1}}{P_{1}}+\frac{d_{2}}{P_{2}} \\
\frac{1}{Q_{\text {tot }}}=\sum \frac{d_{i}}{P_{i}}=\frac{1}{Q_{1}}+\frac{1}{Q_{2}}+\frac{1}{Q_{2}}+\cdots,
\end{gathered}
$$

where $d$ represents the thickness of each layer, $i,\left(d=\sum d_{i}\right)$, and $P$ is the oxygen permeability of each layer. Subscript 1 stands for the polymer film and subscript 2 for the coating.

Oxygen permeability values of coatings were normalized to a thickness of $100 \mu \mathrm{m}\left(Q_{100}\right)$ in order to allow direct comparison of different materials independently of the coating thickness. Five random positions on the film were measured and averaged. 
Water vapour transmission rate (WVTR) was measured according to EN ISO 15106-3 (CEN, 2005) using a Brugger Feinmechanik $\mathrm{GmbH}$ instrument. The test cell consists of two sections separated by the coated film. R.h. in the lower section is $0 \%$ because it is purged with dry nitrogen. R.h. in the upper section is varied using of a frit soaked with a sulfuric acid/water mixture. R.h. is adjusted and is set to $85 \%$ for the measurements. Water vapour that permeates through the film raises r.h. of the upper section and is detected by the electrolytic cell which cleaves water vapour into hydrogen and oxygen. The generated electric current is proportional to the amount of permeated water and is used for calculation of WVTR in $\mathrm{g} \mathrm{m}^{-2} \mathrm{~d}^{-1}$. Two replicates are made and the average value is used for further calculations.

2.5. Food Storage Validation. For sensory as well as chemical validation of the laminates based on whey-coated PET, the selected test food product was buttercheese $(22 \mathrm{~g}$ protein and $26 \mathrm{~g}$ fat/100 g) obtained from the company ÖMA Beer GmbH, Ökologische Molkereien Allgäu, Kisslegg, Germany. The original product is packed under modified gas atmosphere (MAP) of $70 \% \mathrm{CO}_{2}$ and $30 \% \mathrm{~N}_{2}$. Under storage conditions of 8 to $10^{\circ} \mathrm{C}$, it has a shelf life of 45 days. In this study, the packaging regime was modified to vacuum packaging in order to obtain the highest effect onto the food product of the newly developed whey-coated films. A comparison was performed using reference packaging material of PA/PE with $60 \mu \mathrm{m}$ thickness.

The validation of the sensory properties of the packed cheese samples was made by triangle test and consensus sensory profiling, respectively, according to the DIN EN ISO 4120 and DIN 10967-2. The goal is to provide information about any significant change in sensory properties including appearance, odour, taste, texture, and mouthfeel. The protein [18], peroxide (POV) [19] and acidic value (AV) [20], dry matter content by moisture analyser, and fatty acid profile by gas chromatography were determined versus time.

While all ingredients for the whey coating formulations (see Section 2.1) were selected among those approved for food contact (as per EC directive 95/2/EC), EC 10_2011 on Plastic materials and articles intended to come into contact with food was used to test the suitability of the final multilayer films to be used in food packaging applications. Simulants corresponding to buttercheese were used: simulant A consisted of an ethanol solution at 10\% (Panreac S.A, Spain) and simulant D2 consisted of isooctane (Sigma-Aldrich, Spain) replacing the vegetable oil [21]. The global migration was measured after 10 days storage at $40^{\circ} \mathrm{C}$ and expressed in $\mathrm{mg}$ per square $\mathrm{dm}\left(\mathrm{mg} \mathrm{dm}^{-2}\right)$ and compared to the global migration limit in the planned conditions of use of the material of $10 \mathrm{mg} \mathrm{dm}^{-2}$ as set in the regulation.

2.6. Recyclability Tests. The ability to remove the whey protein coating from its carrier film was tested. Different enzymatic detergent formulations can be used depending on the targeted application; for instance, proteases are known to be used to clean fouled dairy filters. One of the enzyme detergents presently marketed for cleaning membrane systems
TABLE 1: Contact angle of water droplet onto used substrates before and after corona treatment and after whey-based coating application.

\begin{tabular}{lcc}
\hline & $\begin{array}{c}\text { Corona-treated } \\
\text { PET }\end{array}$ & $\begin{array}{c}\text { Whey coated } \\
\text { PET }\end{array}$ \\
\hline Contact angle initially $\left(^{\circ}\right)$ & $65 \pm 2$ & $57 \pm 2$ \\
Contact angle after 1 minute $\left(^{\circ}\right)$ & $65 \pm 2$ & $23 \pm 10$ \\
\hline
\end{tabular}

is Terg-a-zyme (Alconox, Inc, NY, USA). Indeed, proteases can cleave and solubilise the protein foulant [22]. Therefore, enzymatic detergents based on enzymes protease dissolved in water at various concentrations were used for the removal of the whey coating [23]. Required duration for whey coating removal from both coated film and laminates was tested at various temperatures into 20 liter glass tank with slight stirring. Assessment of whey removal was done by DSC and FT-IR spectroscopy.

After the removal of the whey-protein-based coating, the mechanical properties of the films were evaluated by tensile test with an Instron 4302 machine. The specimens were "dogbone" stamp cut from the films. The area for the test, defined by an extensimeter, had $6 \mathrm{~mm}$ width and $30 \mathrm{~mm}$ length. The load cell used was $1 \mathrm{kN}$, and test speed was $24 \mathrm{~mm} \mathrm{~min}^{-1}$. All tests were performed at room temperature using at least five specimens for each sample.

2.7. Assessment of Environmental Impact. The study of environmental impact of coated films was realized by Life Cycle Analysis (LCA) from cradle to grave comparing the wheycoated films with standard commercial multilayer films using international standard methodology that consists of four independent elements (ISO 14040, 2006, and ISO 14044, 2006). SimaPro software was used with data from the Ecoinvent database and data on the production of whey-based coating acquired by researchers and manufacturers.

\section{Results}

3.1. Evaluation of Coated Films. Depending on the d.m. content, speed of application, and used coating head, the amount of coating applied varied from 3 to $10 \mathrm{~g} \mathrm{~m}^{-2}$. The samples tested for which further characterizations are reported hereafter had in the range of $6 \mathrm{~g} \mathrm{~m}^{-2}$ per layer and a double pass was done to reach $12 \mathrm{~g} \mathrm{~m}^{-2}$ of whey coating. The coating was applied at 10 meters per minute with a total drying power of $8400 \mathrm{~W} \cdot \mathrm{h}$ for a $20 \mathrm{~cm}$ width coated film. Residual moisture in the coating, as measured by DSC, was below $2 \%$.

The results of contact angles (Table 1) confirmed that, after corona treatment, PET wettability is adequate for waterborne coating deposition and that the whey coating makes the coated surface much more hydrophilic. As such, the coated film does not require a corona treatment before applying a second coating layer and facilitates the application of the adhesive for subsequent lamination. Table 1 also reports the evolution of water contact angle during a period of 60 seconds: whereas the droplet is quite steady on PET, it 
TABLE 2: Results of the optical measurement of the oxygen barrier.

\begin{tabular}{lccc}
\hline Trial & $\begin{array}{c}\text { OTR } \\
\left(\mathrm{cm}^{3}(\mathrm{STP}) \mathrm{m}^{-2} \mathrm{~d}^{-1} \mathrm{bar}^{-1}\right)\end{array}$ & $\begin{array}{c}\text { Q whey coating } \\
\left(\mathrm{cm}^{3}(\mathrm{STP}) \mathrm{m}^{-2} \mathrm{~d}^{-1} \mathrm{bar}^{-1}\right)\end{array}$ & $\begin{array}{c}Q_{100} \text { whey coating } \\
\left(\mathrm{cm}^{3}(\mathrm{STP}) \mathrm{m}^{-2} \mathrm{~d}^{-1} \mathrm{bar}^{-1}\right)\end{array}$ \\
\hline PET & 101 & - & - \\
PET/whey coating/PE & 3.1 & 3.2 & 0.4 \\
\hline
\end{tabular}

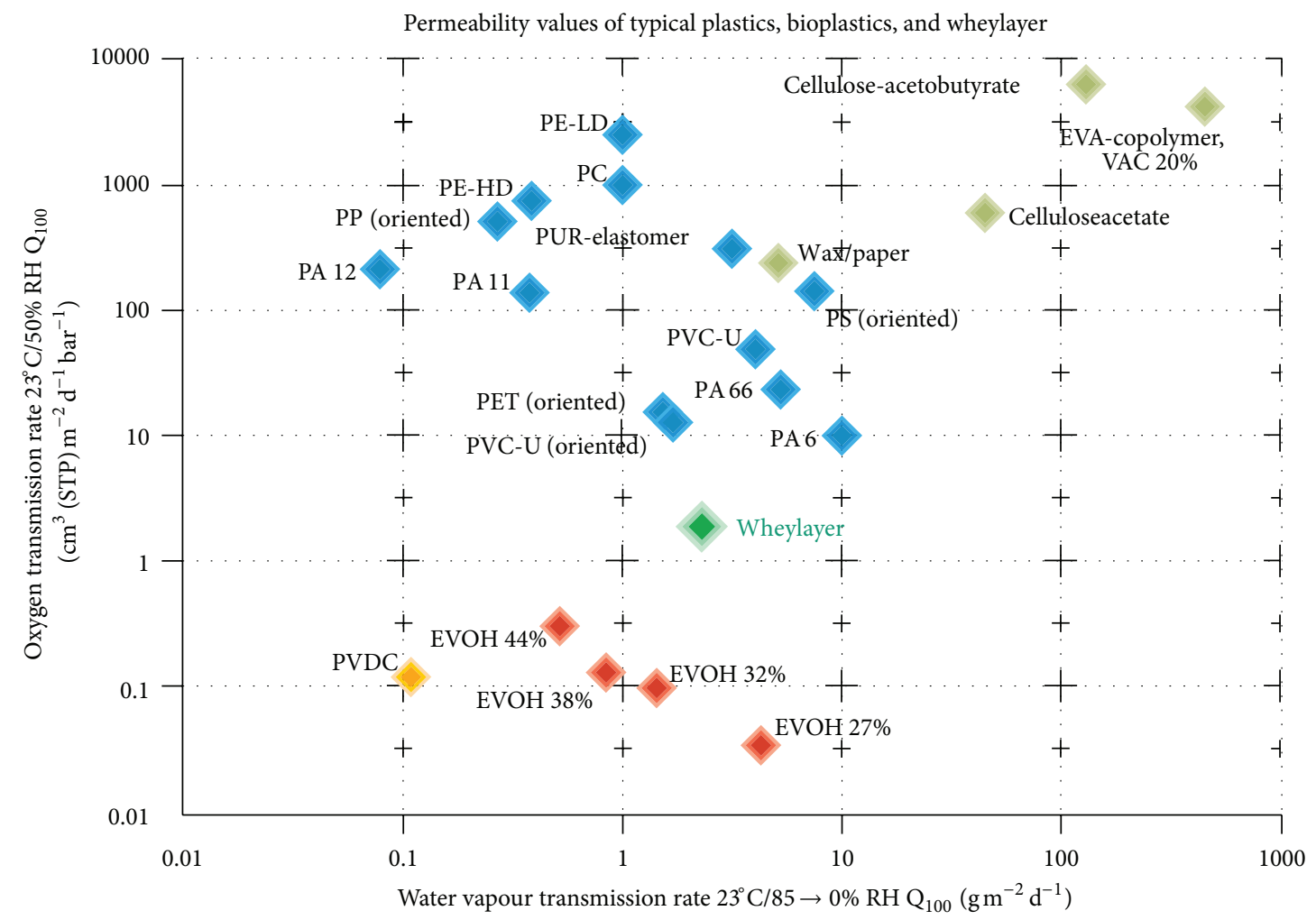

FIGURE 2: Barrier properties of whey-based layer versus other plastics commonly used in the packaging industry normalized to $100 \mu \mathrm{m}$.

tends to wet totally the surface of the coated sample over that time.

3.2. Barrier Properties. The OTR measurement results for the coated PET films after lamination with PE can be found in Table 2 as measured at standard temperature and pressure (STP). The OTR and the $Q_{100}$ of the whey coating were calculated as previously explained. This coating showed a good oxygen barrier and thus an increased oxygen barrier for the resulting coated and laminated films whereby a whey coating of approximately $12 \mu \mathrm{m}$ in a PE/PET sandwich allowed an improvement by a factor 30 of the OTR of the whole. The calculated average $Q_{100}$ values of the coating were $0.4 \mathrm{~cm}^{3}$ (STP) $\mathrm{m}^{-2} \mathrm{~d}^{-1}$ bar $^{-1}$ at $0 \%$ r.h. (Table 2 ).

The WVTRs of whey-coated PET films were measured by a gravimetric method at $23^{\circ} \mathrm{C} / 85 \% \rightarrow 0 \%$ r.h according to DIN 53 122-1. The PET laminate showed a water vapour barrier of $15.8 \mathrm{~g} \mathrm{~m}^{-2} \mathrm{~d}^{-1}$ which is the value of uncoated PET. Thus, it was not possible to calculate the WVTR of the whey coating. Therefore, previously reported values [24] were taken into account for the further representation of the OTR versus WVTR (Figure 2).
The oxygen barrier evolution versus humidity was measured depending on the relative humidity of the measuring gas (Table 3). The variation of the oxygen barrier of PET depending on relative humidity was considered in the calculation. Above $50 \%$ r.h. calculating the oxygen permeability of the whey coating was not possible due to the fact that the permeability of one layer became lower or equal to the permeability of the multilayer structure. The OTR of the whey coating was almost constant within the range of $0-30 \%$ r.h. At $50 \%$ r.h. the $Q_{100}$ raised slightly from 3.8 to $7.9 \mathrm{~cm}^{3}$ (STP) $\mathrm{m}^{-2} \mathrm{~d}^{-1} \mathrm{bar}^{-1}$. The difference between the results reported in Tables 2 and 3 at similar conditions (i.e., at $0 \%$ r.h.) should be explained by the difference of techniques used. Since the optical method is used for fast screening whereas the results in Table 3 are according to the standardized method, those were taken into account in the OTR versus WVTR graph (Figure 2).

As shown in Figure 2, whey-coated films achieved much superior barrier properties compared to other bioplastics (in green). Results also indicate that the OTR values of wheybased coating approach those of EVOH with high ethylene content and are better than PA which is further used for 
TABLE 3: OTR versus r.h. for whey-coated PET films (measured according to DIN 53 380, T3).

\begin{tabular}{lccc}
\hline r.h. [\%] & OTR & $\begin{array}{c}\text { Q whey coating } \\
\left(\mathrm{cm}^{3}(\mathrm{STP}) \mathrm{m}^{-2} \mathrm{~d}^{-1} \mathrm{bar}^{-1}\right)\end{array}$ & $\begin{array}{c}Q_{100} \text { whey coating } \\
\left(\mathrm{cm}^{3}\left(\mathrm{STP}^{-2} \mathrm{~m}^{-2} \mathrm{~d}^{-1} \mathrm{bar}^{-1}\right)\right.\end{array}$ \\
\hline 0 & $\left(\mathrm{~cm}^{3}(\mathrm{STP}) \mathrm{m}^{-2} \mathrm{~d}^{-1} \mathrm{bar}^{-1}\right)$ & 27.4 & 3.8 \\
30 & 22.3 & 26.9 & 3.8 \\
50 & 21.6 & 56.2 & 7.9 \\
\hline
\end{tabular}

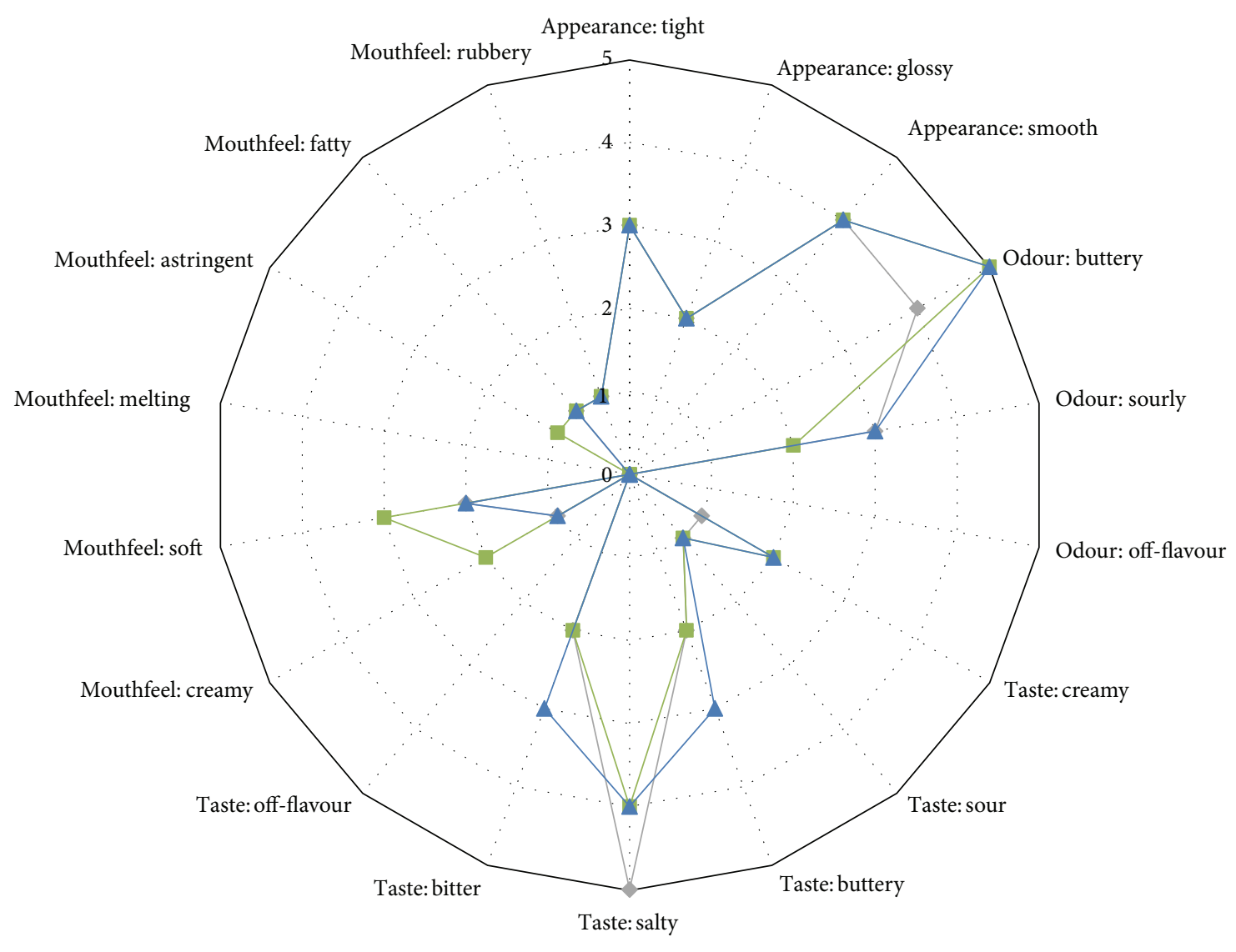

- Fresh buttercheese (t0)

- Buttercheese in reference packaging, vacuum ( $\mathrm{t} 42$ )

- Buttercheese in whey-coating-based packaging, vacuum ( $\mathrm{t} 42)$

Figure 3: Comparison of initial sensory attributes of buttercheese ( $\mathrm{t} 0$ ) with those after 42 days (t42) of storage in whey-coating-based packaging versus reference packaging, both packed under vacuum.

food storage validation. Pending future confirmations of the suitability of all other features, these observations show the potential of the whey-protein-based coatings to substitute other synthetic barrier layers used for food packaging in terms of barrier properties.

3.3. Food Storage Tests. Laminates derived from whey-coated films were tested for storing buttercheese in comparison with fully synthetic reference multilayer films (a PE-/PA- based laminate of $60 \mu \mathrm{m}$ thickness which OTR was below $30 \mathrm{~cm}^{3}$ (STP) $\mathrm{m}^{-2} \mathrm{~d}^{-1}$ bar $^{-1}$ at $23^{\circ} \mathrm{C} / 35 \%$ r.h., therefore better or equal to the whey-protein-coated laminates). The overall shelf life was comparable in both cases and exceeded the duration of the tests that was limited to the shelf life of 42 days specified by the cheese manufacturer. During the sensory triangle testing, the buttercheese stored in the new whey-coated laminates showed a significant difference with the cheese packed in the reference packaging but not with the buttercheese stored in the original packaging (i.e., under modified atmosphere).

Sensory consensus profiling showed very complex results along the storage time but sensory changes had no negative impact on the product properties and no off-flavour was observed (Figure 3 ). It has to be noted that all sensory changes in profiling were in the range of \pm 1 , which represents only minor and hardly significant changes. Indications for the ripening process of the product were observed during storage of buttercheese in both materials. In this example, 
the taste was slightly more buttery in the buttercheese stored in the whey coating-based material, whereas the mouthfeel of the buttercheese stored in the reference packaging was slightly creamier and softer as observed in the triangle testing. More significant differences may appear using longer storage beyond the shelf life expiration in future research.

In all samples the peroxidic value was below 1 over storage time. Thus, the fat extracted from the buttercheese over storage time in the different packaging solutions is not seen as rancid or oxidised even though the method of extracting the fat also bears a high source for deviation. The POV results are additionally supported by the measurements of acidic value as well as the sensory analysis in which no rancid flavours were detected. This correlates also with the results from fatty acid profiles in which no significant difference over the shelf life in either packaging solution was observed as the mean ratio [\%] of saturated and unsaturated fatty acids stays $65: 35$ over storage time.

Since the dry matter of the validation product was stable over storage and comparable between the 2 packaging materials, it can be assumed that the humidity barrier of whey-based packaging was sufficiently close to that of the reference material (WVTR, resp., in the range of 1.7 to $6.7 \mathrm{~g} \mathrm{~m}^{-2} \mathrm{~d}^{-1}$ depending on the type of PE used for the whey-based laminate of ca. $45 \mu \mathrm{m}$ versus $3 \mathrm{~g} \mathrm{~m}^{-2} \mathrm{~d}^{-1}$ for the reference packaging film used of $60 \mu \mathrm{m})$.

Further tests also showed that laminates including the whey coating fulfilled food safety regulations in terms of migration since the measured values for global migrations in the 2 specified stimulants were below the detection limits of $1 \mathrm{mg} \mathrm{dm}^{-2}$.

3.4. Recyclability of Multilayer Films. In terms of end of life, whey proteins can be hydrolyzed by different enzymes in specific conditions to make multilayer films recyclable [25], as a result of the separation of the layers made up of conventional petroleum-based plastics. Indeed, the recycling process consists of the shredding of the films, the washing, and the separation of each plastic flakes before each can be recycled independently. The washing stage of the recycling process can be easily adapted by the substitution of used chemical detergent by a selected enzymatic detergent.

Corresponding enzyme types, dosage, time, temperature, and $\mathrm{pH}$ value optima, which are further applicable to industrial waste recycling, were determined as reported in Table 4 [26]. Trials of cleaning were performed simply by soaking samples of films in a $2 \%$ by weight of Terg-a-zyme for 24 hours at room temperature, thus simulating a presoaking treatment of the films. The removal of the protein was faster and more efficient under mild stirring. Similar results were obtained with other protease-based detergents.

In each case the coating was removed as evidenced by FT-IR tests. For example, Figure 4 reports the FT-IR spectra of the PET film and cast film obtained using the coating formulation and the FT-IR spectra of coated PET after washing with enzymatic detergent. The characteristic peak of protein between 3500 and $3000 \mathrm{~cm}^{-1}$ is not present
TABLE 4: Weight loss in PET samples coated with whey and treated with Terg-a-zyme.

\begin{tabular}{lc}
\hline Time-enzyme concentration & Weight loss (\%) \\
\hline $24 \mathrm{~h}-2 \%$ no stirring & 15.8 \\
$4 \mathrm{~h}-1 \%$ stirring & 14.3 \\
$2 \mathrm{~h}-2 \%$ stirring & 14.7 \\
\hline
\end{tabular}

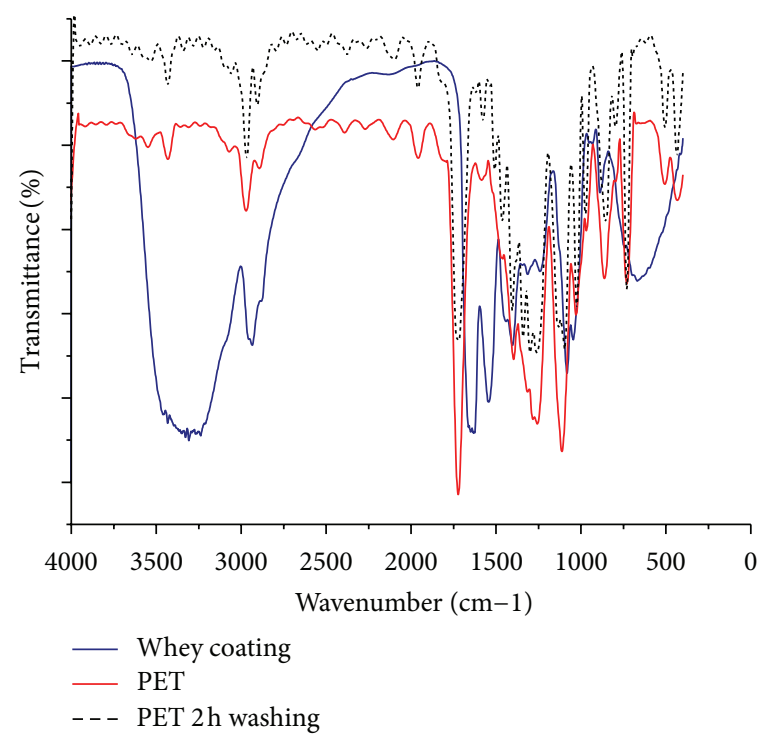

FIGURE 4: FT-IR spectra of PET, whey coating and coated PET after $2 \mathrm{~h}$ washing.

in samples treated with enzymatic detergent and the IR signature corresponds to that of PET.

Due to the difference in density between the substrates that can be assembled using a whey coating in a multilayer packaging such as in this case the PE/whey coating/PET, it becomes possible to recycle the 2 substrates independently after density separation once the whey coating has been removed. The possibility of reusing the recovered substrates forming the multilayer films was also tested by performing mechanical tests. Multilayer films based on PET and PE and the whey coating with a thickness of ca. $45 \mu \mathrm{m}$ presented mechanical properties compatible with the requirements of applications such as food packaging with a strain at break of $70 \%$, Young's Modulus of $850 \mathrm{MPa}$, and Ultimate Tensile Strength of $22 \mathrm{MPa}$. Comparison of Young's modulus evolution versus temperature of whey-based-coated films, coating (determined applying the theory of composite materials in "isodeformation conditions"), and substrate can be found in a previous paper [13]. The changes in mechanical properties observed for the separated PE and PET films after the removal of the whey coating were not too significant (Table 5). Further tests such as melt flow index would allow determining for which applications the recovered materials would fit.

3.5. Assessment of Environmental Impact. Overall, as showed hereafter by preliminary non-peer-reviewed data of LCA, the use of whey-based coating could reduce $\mathrm{CO}_{2}$ emissions 


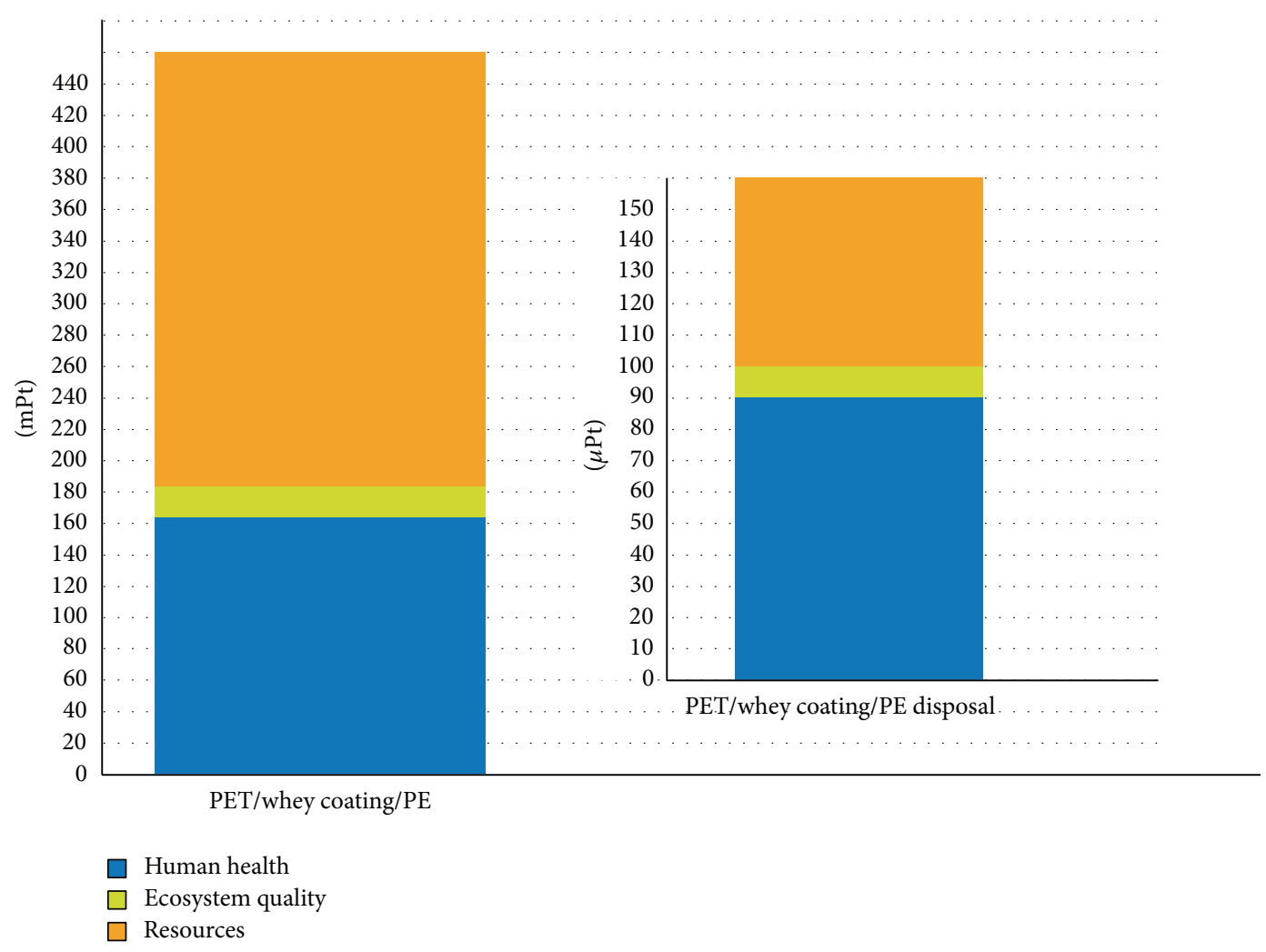

FIGURE 5: Environmental damage for PET/whey coating/PE films and magnified impact of the whey-coating disposal.

TABLE 5: Mechanical properties of the PE and PET films before and after enzymatic removal of the interim whey coating from the multilayer films.

\begin{tabular}{lccc}
\hline Sample & $\begin{array}{c}\text { Stress at yield } \\
{[\mathrm{MPa}]}\end{array}$ & $\begin{array}{c}\text { Stress at break } \\
{[\mathrm{MPa}]}\end{array}$ & $\begin{array}{c}\text { Strain at break } \\
{[\%]}\end{array}$ \\
\hline PE initially & 12 & 30 & 150 \\
PE after washing & 10 & 19 & 400 \\
PET initially & 95 & 190 & 35 \\
PET after washing & 100 & 150 & 25 \\
\hline
\end{tabular}

and consumption of resources in packaging production. Nevertheless, the LCA has to be performed comparatively for each relevant multilayer structure. Straightforward data regarding the difference in the production stage of the whey coating indicates a $15 \%$ reduction of environmental impact versus synthetic counterparts such as $\mathrm{EVOH}$ or PA at similar weight. These figures were obtained on prototype production and could be improved by increasing the energy efficiency at higher production speed. Nevertheless, in a multilayer film, the layer acting as a barrier is relatively thin, leading to a "dilution" of this advantage. It is estimated that a $12 \mu \mathrm{m}$ whey coating could be needed to compete with a thinner $8 \mu \mathrm{m}$ layer of $\mathrm{EVOH}$, or a $20 \mu \mathrm{m}$ PA but this would depend on the requirements of the food to be packed. Indeed, the PA-based reference films used for the previously reported food storage validation had a much higher thickness than the multilayer based on the whey coating ( $60 \mu \mathrm{m}$ versus $45 \mu \mathrm{m})$. In this real case story, a further saving in impact of $45 \%$ is envisaged due to weight reduction, which would sum up for about a $60-65 \%$ lower impact of production and processing of the multilayer films, while still competing in terms of food preservation.

Overall, the highest benefit from the use of whey coating is the saving in emissions and energy due to the possibility of recycling the polymeric layers that compose the multilayer as opposed to their conventional incineration. Figure 5 reports the values of damage categories for the whey coating evaluated with Eco Indicator 99 Egalitarian Method that obtains a long-term perspective of environmental damage. As shown in this figure, the impact of the disposal of water eventually containing organics resulting from the wheycoating degradation and the inactivated enzymes is very low and in fact two orders of magnitude lower than incineration.

In the present study, a benefit of 19\% for Human Health, of $35 \%$ on Ecosystem Quality, and of $14 \%$ on Resources is attested by the use of multilayer films based on whey coating versus those based on $\mathrm{EVOH}$. In the case of the multilayer films based on the whey coating with thickness of $45 \mu \mathrm{m}$ compared with the commercial films containing PA with thickness $60 \mu \mathrm{m}$ that was used in the present study for food validation, the difference in impact is over $60-80 \%$ reduction in the damage categories.

When comparing the two materials throughout their life cycle, no obvious differences can be identified during the transport, use, and manufacturing steps since the impact of coextrusion and lamination are not significantly different. Therefore, the main advantages in the use of the whey-based 
coating are in terms of raw materials and of end of life. Indeed, resources are safeguarded on the one hand through the use of a waste by-product (whey) versus a petroleum-derived material (EVOH or PA) and on the other hand through the possibility of recovering the other films such as PE and PET and thus recycling them as opposed to the incineration of commercial multilayer films.

\section{Conclusion}

This study reveals the potential for using whey coating in packaging due to the number of environmental advantages that it presents compared to barrier polymers which are available today, while maintaining required technical performance.

Indeed, the whey coating achieved superior barrier properties compared to other bioplastics and approached those of synthetic barrier layers, such as EVOH. Derived laminates were shown to be suitable packaging films for sensitive food products such as buttercheese since it had no negative sensory influence and the majority of sensory changes resulted from the cheese ripening process and not from the packaging.

As opposed to previous studies, the application and drying of the whey-protein-based coating was done at semiindustrial production speeds and the importance of the process to control the structure of the proteins and the resulting properties of the coating was described in a patent [14].

The holistic "cradle to grave" environmental approach used for this development allowed maximizing the sustainability of the material. Indeed, as opposed to depleting fossil resources normally used, the developed low carbon footprint biosourced formulation valorizes a by-product from the agrofood industry.

Through enzymatic cleaning compatible with current plastic recycling operations, the developed coating can be removed allowing the recycling of multilayer packaging thereby responding to legislative demands in terms of the amount of recycled packaging. Therefore, in addition to the savings in terms of raw materials, whey-coated laminates have a much lower environmental impact compared to those based on EVOH or on polyamide in particular at end of life.

\section{Authors' Contribution}

E. Bugnicourt and M. Schmid contributed equally to this work.

\section{Acknowledgments}

The authors wish to acknowledge the funding from the European Community's Seventh Framework Programme (FP7/2007-2013) for the research leading to these results under Grant agreement no. 218340-2 through the WHEYLAYER project (http://www.wheylayer.eu/).

\section{References}

[1] J. Jasko, E. Skripsts, V. Dubrovskis, E. Zabarovskis, and V. Kotelenecs, "Biogas production from cheese whey in two phase anaerobic digestion," Engineering for Rural Development, pp. 373-376, 2011.

[2] C. I. Onwulata, R. P. Konstance, P. H. Cooke, and H. M. Farrell, "Functionality of extrusion-texturized whey proteins," Journal of Dairy Science, vol. 86, no. 11, pp. 3775-3782, 2003.

[3] G. Braunegg, A. Atlic, M. Dias, and M. Koller, "Novel biotechnological processes for production of polymers, chemicals, and biofuels from waste," in Workshop on Green Olympics, Green Materials and Biofuels, pp. 14-15, Beijing, China, December 2008.

[4] K. Khwaldia, C. Ferez, S. Banon, S. Desobry, and J. Hardy, "Milk proteins for edible films and coatings," Critical Reviews in Food Science and Nutrition, vol. 44, no. 4, pp. 239-251, 2004.

[5] K. S. Miller and J. M. Krochta, "Oxygen and aroma barrier properties of edible films: a review," Trends in Food Science and Technology, vol. 8, no. 7, pp. 228-237, 1997.

[6] M. Gällstedt, Films and Composites Based on Chitosan, Wheat Gluten or Whey Proteins -Their Packaging Related Mechanical and Barrier Properties, Fibre and Polymer Technology Department, Kth, Sweden, 2004.

[7] S. I. Hong and J. M. Krochta, "Whey protein isolate coating on LDPE film as a novel oxygen barrier in the composite structure," Packaging Technology and Science, vol. 17, no. 1, pp. 13-21, 2004.

[8] J. W. Lee, S. M. Son, and S. I. Hong, "Characterization of proteincoated polypropylene films as a novel composite structure for active food packaging application," Journal of Food Engineering, vol. 86, no. 4, pp. 484-493, 2008.

[9] R. Sothornvit, D. S. Reid, and J. M. Krochta, "Plasticizer effect on the glass transition temperature of beta-lactoglobulin films," Transactions of the American Society of Agricultural Engineers, vol. 45, no. 5, pp. 1479-1484, 2002.

[10] K. L. Dangaran and J. M. Krochta, "Preventing the loss of tensile, barrier and appearance properties caused by plasticiser crystallisation in whey protein films," International Journal of Food Science and Technology, vol. 42, no. 9, pp. 1094-1100, 2007.

[11] T. H. McHugh and J. M. Krochta, "Sorbitol- vs glycerolplasticized whey protein edible films: integrated oxygen permeability and tensile property evaluation," Journal of Agricultural and Food Chemistry, vol. 42, no. 4, pp. 841-845, 1994.

[12] M. Ozdemir and J. D. Floros, "Optimization of edible whey protein films containing preservatives for mechanical and optical properties," Journal of Food Engineering, vol. 84, no. 1, pp. 116-123, 2008.

[13] M. Schmid, K. Dallmann, E. Bugnicourt et al., "Properties of whey protein coated films and laminates as novel recyclable food packaging materials with excellent barrier properties," International Journal of Polymer Science, vol. 2012, Article ID 562381, 7 pages, 2012.

[14] M. Schmid, K. Noller, F. Wild, and E. Bugnicourt, "Whey protein coated films," Patent PCT/ IB2011/053271, 2011.

[15] M. Schmid, K. Dallmann, F. Wild, and K. Noller, Whey protein coated plastic films to improve barrier properties of food packaging materials (Poster). Sonderschau "Nachhaltigkeit \& Corporate Social Responsibility"-Intermopro. Düsseldorf, Germany, 2010.

[16] K. Müller, Packstoffe in Der Optik. IVlV-Merkblatt Für Die Prüfung Von Folien Und Formteilen Aus Kunststoff, Fraunhofer IVV, Freising, Germany, 2011. 
[17] S. I. Hong and J. M. Krochta, "Oxygen barrier performance of whey-protein-coated plastic films as affected by temperature, relative humidity, base film and protein type," Journal of Food Engineering, vol. 77, no. 3, pp. 739-745, 2006.

[18] Amtliche Sammlung von Untersuchungsverfahren nach $\$ 35$ LMBG. 1981: L 06.00-7.

[19] Amtliche Sammlung von Untersuchungsverfahren nach $\$ 35$ LMBG. 1991: L 13.00-6.

[20] Amtliche Sammlung von Untersuchungsverfahren nach $\$ 35$ LMBG. 1987: L 13.00-5.

[21] K. H. Lund, L. Lillemark, and J. H. Petersen, "A DANREF certified reference plastic for measurement of overall migration into the food simulant olive oil by single sided testing," Fresenius' Journal of Analytical Chemistry, vol. 367, no. 8, pp. 742-747, 2000.

[22] C. G. Kumar, R. K. Malik, and M. P. Tiwari, "Novel enzymebased detergents: an Indian perspective," Current Science, vol. 75, no. 12, pp. 1312-1318, 1998.

[23] J. K. A. Kamal, T. Xia, S. K. Pal, L. Zhao, and A. H. Zewail, "Enzyme functionality and solvation of Subtilisin Carlsberg: from hours to femtoseconds," Chemical Physics Letters, vol. 387, no. 4-6, pp. 209-215, 2004.

[24] E. Bugnicourt, M. Schmid, O. Mc Nerney, and F. Wild, Wheylayer: The barrier coating of the future. Coating International, 2010.

[25] P. Cinelli and A. Lazzeri, Le Proteine nel Settore Degli Imballaggi Wheylayer. Bio-Imballaggio Derivato dal Siero del Latte, Biopolpack, Parma, Italy, 2010.

[26] P. Cinelli, A. Lazzeri, and E. Bugnicourt, Wheylayer-recycling methods for polymer films coated with whey protein, Compack Chennai, Complete Packaging Expo And Trade Fair, Chennai., India, 2011. 

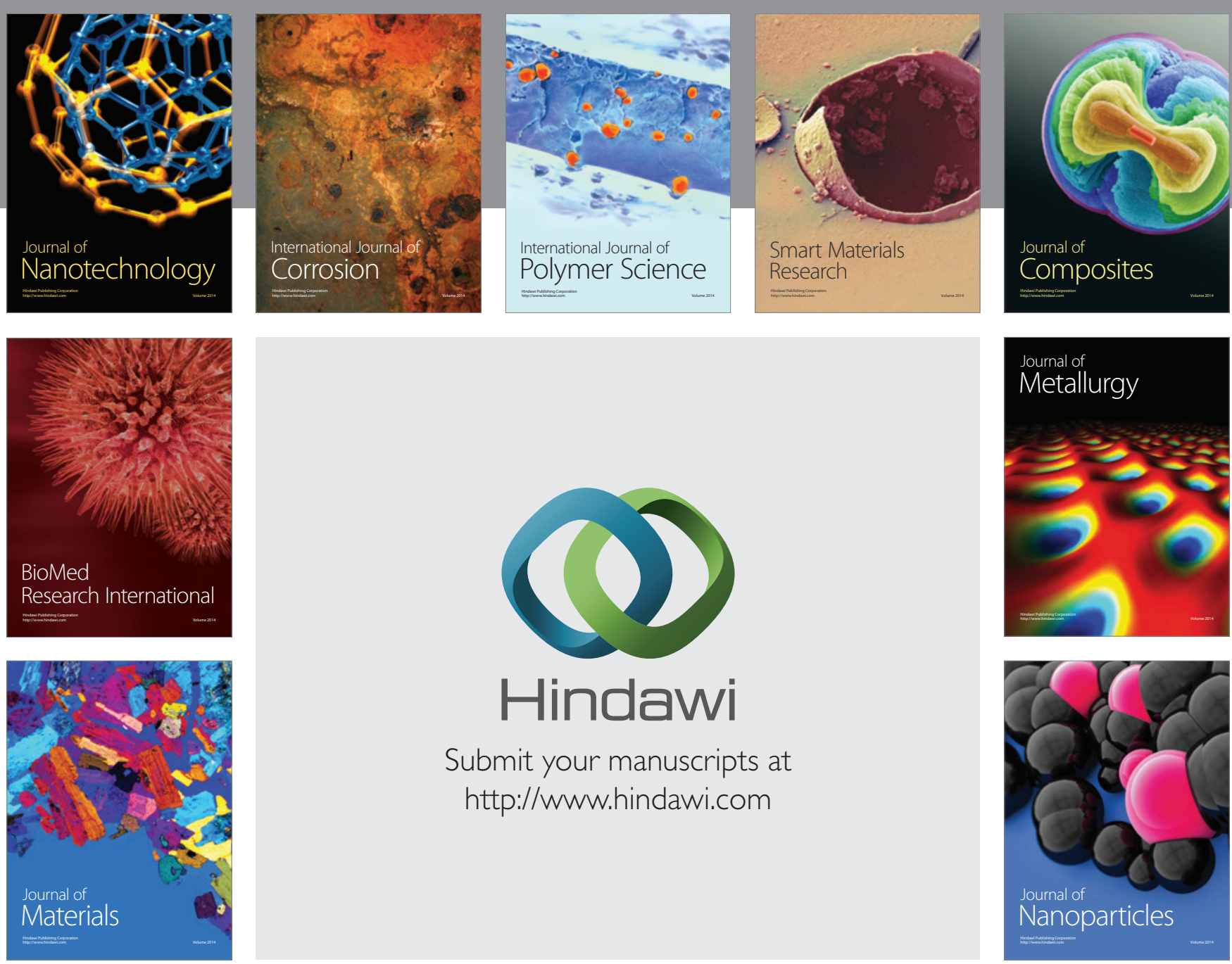

Submit your manuscripts at http://www.hindawi.com
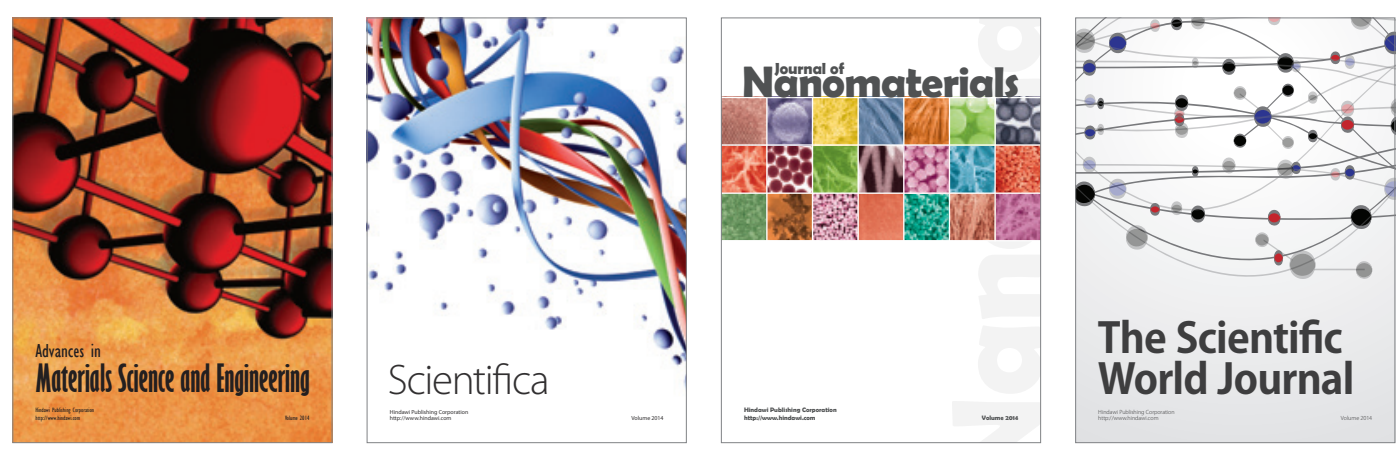

\section{The Scientific World Journal}
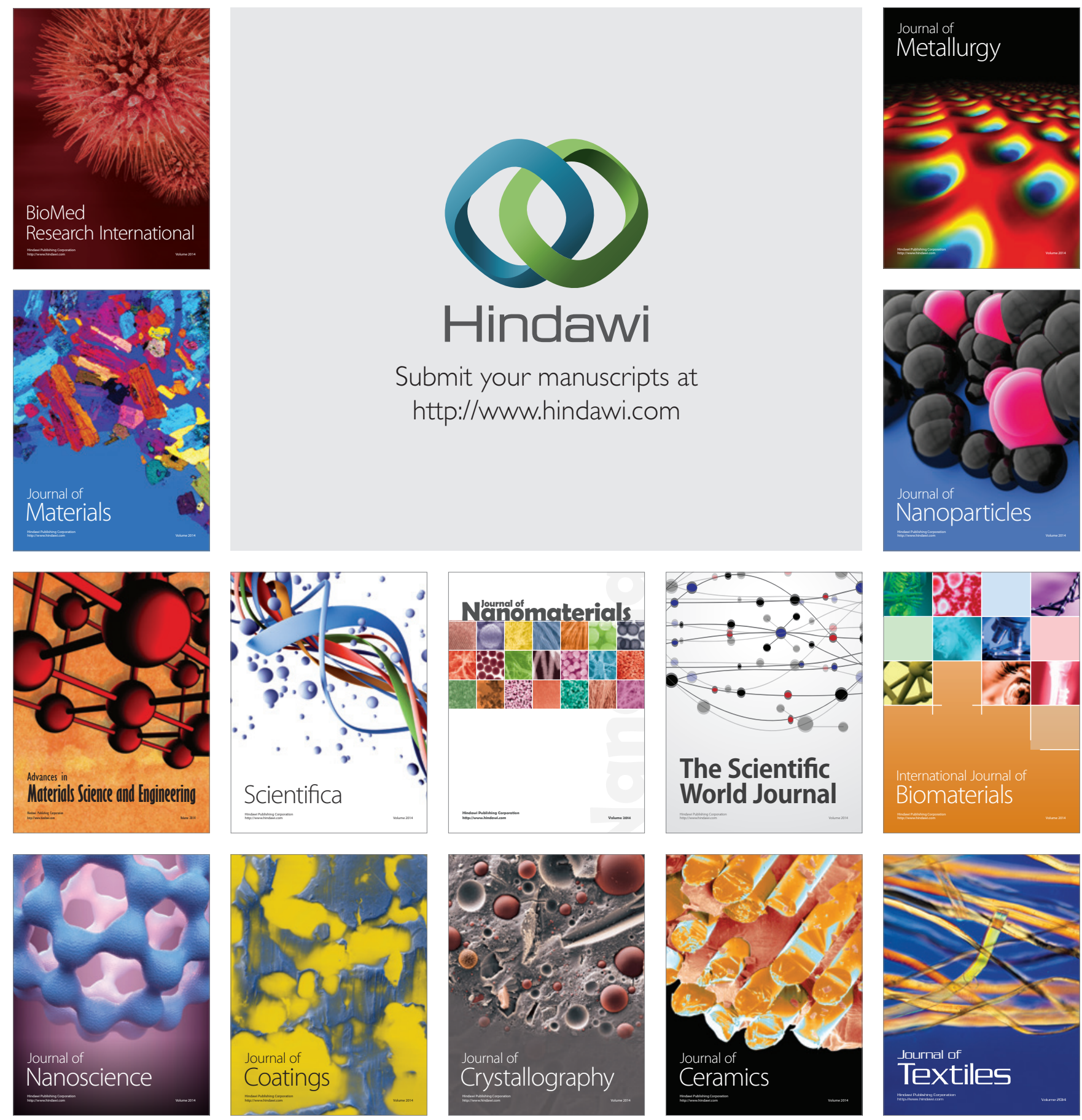